\title{
BEHAVIOUR OF LONG-LASTING STRESS RELAXATION OF VARIOUS TYPES OF YARNS
}

\author{
Ginta Laureckienè*, Rimvydas Milašius \\ Department of Materials Engineering, Faculty of Mechanical Engineering and Design, \\ Kaunas University of Technology, Studentu str. 56, LT-51424 Kaunas, Lithuania, \\ ${ }^{*}$ Corresponding author: ginta.laureckiene@ktu.It
}

\begin{abstract}
:
The main goal of this researcher is estimating of the possibility of long-lasting (even until 200,000 s) stress relaxation by empirical investigation, which was performed for a few thousands of seconds. The empirical investigations of longlasting stress relaxation of different types of yarns (multifilament polyester, cotton and woollen) at different levels of elongation, i.e. at 3\%, 5\%, $7 \%$ and 10\%, were carried out. The method of long-lasting relaxation behaviour prediction by the break-point of relaxation rate as well as the linear dependence of second part of relaxation were used. It was found that the behaviour of relaxation can be described using time logarithmic scale by two straight lines, and the value of stress relaxation in long time period could be estimated by the second line. The break-point of relaxation rate of all kinds of yarns occurs in the area of 100-200 s after relaxations started. The obtained results showed that the place of relaxation break-point depends on the level of elongation but does not depend on the type of yarns.
\end{abstract}

\section{Keywords:}

stress relaxation, polyester, cotton, woollen yarn

\section{Introduction}

Time-dependent processes in textile products are often observed when deformed products are relaxed. Under stretched conditions, the stress of textile materials gradually decreases. This phenomenon, when stresses in materials decrease in response to the same amount of generated strain, is known as stress relaxation and was investigated by various researchers for a long time. The definition of stress relaxation can be described as the viscoelastic stress decrease over time. It is not easy to estimate the stress relaxation properties because they depend not only on a raw material (kind of polymer) of textile, but also on structure of textile materials and yarns [1]. The relaxation properties are very important for various kinds of textiles and especially for textiles that are used in technical application (ropes, conveyor belts, etc.) and for products that are used under a long-lasting stress. The prediction of relaxation behaviour is very important for further usage of textile materials [2]. Falls from height is one of the most common causes of serious accidents at work and it depends on the textile material, which is used for protection against falls in industry, manufacture, transport and warehousing [3].

Stress relaxation explains structural responses of material against stresses and is one of the main mechanical behaviour of textile materials. Stresses decrease in a time under constant strain, and understanding of behaviour of the stress relaxation process is very important when desirable properties are required in a textile for a long period of time [4,5]. In textiles as well as in other polymeric materials, the macromolecular conformation has to be at a non-equilibrium state upon being stressed and the movement of chain segments would take place to reduce or relieve the internal stress in time [6].
Many empirical studies of yarns of different origin, and fibres and structures were published. Some interesting points have observed by Vangheluwe [7], Vitkauskas [8], Kothari [9], Nachane [10], Manich [11, 12], and others to evaluate the stress relaxation of fabrics, yarns and polymeric materials [13-21]. The authors presented studies in the stress relaxation of various fibres under the effect of moisture, temperature as well as level and speed of deformation.

Already in 1954, Meredith [13,14] stated that the stress does not reach a constant value even after 2 weeks. Suhara et al. [15] have studied the stress relaxation behaviour at different strain levels and strain rates. They found that the rate of relaxation and crossover time depend on the strain level and strain rate. In the works of Geršak et al. [16, 17], relaxation phenomena of fabrics containing elastane yarn was investigated. The authors found a longer relaxation time of fabrics with the highest content of elastane. Manich et al. [12] investigated the effect of stretching on the relaxation behaviour and they found that the relaxation can be attributed to bonding breakages under stress over the time according to the bonding energy. They claimed that the energy of bonds, linking macromolecules in a filament can be classified according to the relaxation time. The higher the energy, the higher the relaxation time. Van Miltenburg [18] investigated the relation between tensile modulus and stress relaxation and found that the modulus-elongation curve of different fibres (polyester, polyamide, viscose rayon and aramid) strongly correlates with the residual stress. The stress relaxation behaviour of natural fibers were studied by many researchers [22-26] too. Wool, silk and cotton exhibit similar behaviour in the early process of stress relaxation. Munakata [22] showed that the stress relaxation process could be divided into two stages: the first rapid relaxation of stress may be 
attributed to the non-crystalline regions of woollen fibers, and the second stage to the crystalline regions. Chapman [24] investigated fibre's relaxation for time until $60,000 \mathrm{~s}$ and found a relationship between the stress relaxation and the time taken to recover for a given set. As fibers are not linear viscoelastic under all conditions, the recovery could be predicted from their stress relaxation behaviour using the Boltzmann superposition principle [24]. Natural fibers, such as cotton, wool and flax, are hydrophilic, i.e. their surface has bonding sites for water molecules [19]. One study [26] was focussed on understanding of the effects of humidity and the ratio of woollen and cotton fibers on the initial tensile and tensile stress relaxation properties of the yarns. The authors found that wool/cottonblended yarns have high hygroscopicity, high water absorption properties and a low stress relaxation rate at high relative humidity. In Refs. [27-32], various properties of relaxation, such as creep, inverse stress relaxation of various types of yarns and fibres (even such as carbon nanotube (CNT) yarns) were investigated. Zhang et al. [27] showed that CNT yarns have a resistance against creep and stress relaxation. They found that the stress relaxed less than $15 \%$ when a two-ply nanotube yarn was held for $20 \mathrm{~h}$ at $6 \%$ strain, and the majority of the stress relaxation occurred within the first $20 \mathrm{~min}$. This process was largely due to the viscoelastic nature of the materials.

Hashemi et al. [28] and Ardakani et al. [29] analysed the stress relaxation in knitting materials and it was found to depend on the structure of the knit. The investigations of stress relaxation in these works were carried out till $1800 \mathrm{~s}$ and it was found that the three-component Maxwell's model with parallel-connect nonlinear spring reflects the relaxation behaviour of investigated materials better than others. Unfortunately, authors did not investigate long-lasting relaxation. The relaxation behaviour until $2000 \mathrm{~s}$ can be described as it is proposed by authors, but it is impossible to predict relaxation behaviour by presented model, for example, after $100,000 \mathrm{~s}$. It is the main lack of all theoretical models - the relaxation behaviour can be predicted by them only until the time of empirical investigations.

While analysing various results of empirical and theoretical investigations, it was noted that completely distinct relaxation processes are happening due to the movement and regrouping of elements of the textile fibre structure. Due to the high differences in structure of fibres, the relaxation behaviour could be different and it is especially visible for woollen fibres, as the protein fibres have an even more complex physical and chemical structure. Therefore, it was found that the stress relaxation behaviour in long-lasting relaxation (more than $10,000 \mathrm{~s}$ ) exhibits some difference from the behaviour in a short time relaxation $[2,8,13,16,23-$ $29,32]$. The stress relaxation in initial time of relaxation can be very well described by the logarithmical curve. While after $10,000 \mathrm{~s}$, the differences between empirical and calculated by initial relaxation curve values increases. In our previous works [2, 32], this phenomenon has been proved by the investigations of the long-lasting stress relaxation of polyester yarns. In presented work, the possibility of the long-lasting stress relaxation prediction by two stages of the relaxation rate of three different types of yarns (polyester, cotton and woollen) were analysed and the influence of strain level on the behaviour of stress relaxation was investigated. The main goal of present investigations is to estimate the possibility of the long-lasting (even until 200,000 s) stress relaxation by the empirical investigation, which was done for a few thousands of seconds.

\section{Experimental}

\section{Materials and methods}

Three different types of fibres and yarns were taken for the experimental investigations: the multifilament polyester (PET) yarn with linear density of 29.9 tex, the cotton yarn with linear density of 25 tex $\times 2$ and the woollen yarn with linear density of 25 tex. These kinds of yarns were chosen with intention to test very different structures of the yarns - multifilament (polyester), spun single yarn (wool) and spun double yarn (cotton). The investigated yarns are used for industrial needs and were chosen from JSC 'Vegateksa'. Only in the case of acceptance of method of long-lasting relaxation prediction for all three kinds of yarns, it is possible to state that this method can be acceptable for other kinds of yarns, too. All specimens were investigated at a temperature of $20 \pm 2^{\circ} \mathrm{C}$ and a relative humidity of $65 \pm 4 \%$; the Zwick/Roell universal materials testing machine was used for the investigation of yarn's tensile properties; a gauge length of $500 \mathrm{~mm}$ was set in the test; the extension speed was $500 \mathrm{~mm} /$ min. All testing parameters were chosen according standard EN ISO 2062:2010. The tensile properties of the investigated yarns are presented in Table 1. All tests were repeated five times and average values was calculated. The coefficient of variation of all tests is lower than $2 \%$ for strength values, and lower than $7 \%$ for elongation values.

The same testing machine Zwick/Roell was used for the stress relaxation tests. Specimens were stretched at a speed of $500 \mathrm{~mm} / \mathrm{min}$ up to strain level $(3 \%, 5 \%, 7 \%$ and $10 \%)$ and held in this position for a particular amount of time. The stress was recorded as a function of the time (from $1 \mathrm{~s}$ up to $200,000 \mathrm{~s}$ ). Complete equipment for such research and stretching machine was operated by testXpert $\circledast$ software at the gauge length of $500 \mathrm{~mm}$, and load cell pressure of $50 \mathrm{~N}$.

Table 1. Mechanical properties of the investigated yarns

\begin{tabular}{|c|c|c|c|}
\hline Yarn & Linear density (tex) & Specific stress (cN/tex) & Strain (\%) \\
\hline Multifilament polyester & 29.4 & 61.53 & 13.34 \\
\hline Cotton & $25 \times 2$ & 9.46 & 7.41 \\
\hline Woollen & 25 & 5.59 & 12.30 \\
\hline
\end{tabular}


The relaxation process was investigated by the fixed elongation method, i.e. the test specimens were stretched at $3 \%, 5 \%, 7 \%$ and $10 \%$. If a yarn is stretched up to given strain and held at the same strain for particular time, the stress decreases during the time. The stress relaxation was calculated as ratio $\left(P / P_{0}\right)$, where $P_{0}$ is the initial stress at zero time ( $t=0 \mathrm{~s})$ and $P$ is the stress at subsequent times [2]. Stress relaxation curves were mathematically described by calculations from a series of experimental points, i.e. stress relaxation values were measured after $1,2,5,10,20,50,100$, $200,500,1000,2000,5000,10000,20000,50000,100000$, $200000 \mathrm{~s}$ for each curve.

By means of an earlier method presented, it was proposed to describe these experimental points with two straight lines [2]. The average curve of the relaxation calculated from five relaxation curves was used for the investigations. The relative error between experimental values and those calculated by the straight line equation $(\delta)$ for all experimental points of the stress relaxation curve is calculated as

$$
\delta_{i}=\frac{\left(P / P_{0}\right)_{e}-\left(P / P_{0}\right)_{c}}{\left(P / P_{0}\right)_{e}} \times 100 \%,
$$

where: $\left(P / P_{0}\right)_{\mathrm{e}}$ - experimental values of stress relaxation, $\left(P / P_{0}\right)_{c}$ - stress relaxation values calculated by straight line equations.

The maximum relative error between experimental and calculated values $\left(\delta_{\max }\right)$ by the straight-line equation was used for investigations.

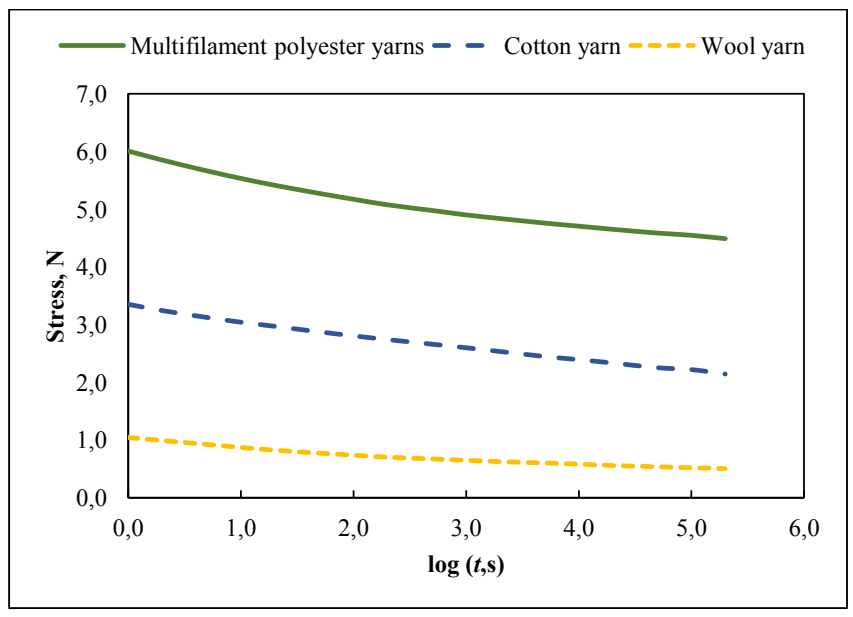

Figure 1. Stress relaxation curves of yarns at $7 \%$ of strain elongation.

\section{Results and discussion}

In the first stage of investigations, all types of the yarns were stretched in four different strain levels - at elongation of $3 \%$, $5 \%, 7 \%$, and of $10 \%$. In Figure 1, the typical stress relaxation curves of the yarns at $7 \%$ of the strain elongation are presented in a logarithmic time scale.

As it is seen from the Figure 1, the shape of the stress relaxation curves of all the yarns are similar - the rate of stress relaxation in the initial part is a bit higher than on the end of the investigations. The results obtained under the long-lasting stress relaxation (until 200,000 s) are presented in Table 2.

Table 2. Results of relative stress relaxation of the multifilament polyester, cotton and woollen yarns at different elongations

\begin{tabular}{|c|c|c|c|c|c|c|c|c|c|c|c|c|}
\hline \multicolumn{2}{|c|}{ Time } & \multicolumn{11}{|c|}{$P / P_{0}(\%)$} \\
\hline \multirow{2}{*}{$t(s)$} & \multirow{2}{*}{$\begin{array}{c}\log t \\
\text { (s) }\end{array}$} & \multicolumn{4}{|c|}{ Multifilament polyester yarn } & \multicolumn{3}{|c|}{ Cotton yarn } & \multicolumn{4}{|c|}{ Woollen yarn } \\
\hline & & $3 \%$ & $5 \%$ & $7 \%$ & $10 \%$ & $3 \%$ & $5 \%$ & $7 \%$ & $3 \%$ & $5 \%$ & $7 \%$ & $10 \%$ \\
\hline 1 & 0.00 & 88.30 & 89.05 & 90.77 & 94.71 & 88.63 & 86.29 & 86.00 & 91.24 & 87.20 & 85.54 & 86.49 \\
\hline 2 & 0.30 & 84.96 & 86.00 & 88.41 & 93.11 & 86.13 & 83.54 & 83.21 & 88.21 & 83.27 & 81.31 & 82.31 \\
\hline 5 & 0.70 & 80.93 & 82.30 & 85.55 & 91.71 & 83.32 & 80.46 & 80.12 & 83.42 & 77.82 & 75.73 & 76.45 \\
\hline 10 & 1.00 & 78.03 & 79.70 & 83.59 & 89.84 & 81.23 & 78.32 & 78.02 & 79.45 & 73.59 & 71.48 & 71.89 \\
\hline 20 & 1.30 & 75.45 & 77.29 & 81.79 & 88.61 & 79.10 & 76.23 & 76.19 & 75.66 & 69.67 & 67.58 & 67.46 \\
\hline 50 & 1.70 & 72.14 & 74.37 & 79.64 & 87.13 & 76.06 & 73.26 & 73.72 & 70.62 & 64.84 & 63.30 & 62.17 \\
\hline 100 & 2.00 & 69.72 & 72.32 & 78.12 & 86.07 & 73.61 & 71.42 & 71.96 & 68.28 & 61.63 & 60.50 & 58.53 \\
\hline 200 & 2.30 & 67.52 & 70.51 & 76.67 & 85.06 & 71.27 & 69.62 & 70.30 & 64.38 & 58.47 & 57.68 & 56.48 \\
\hline 500 & 2.70 & 64.88 & 68.31 & 75.17 & 83.84 & 69.44 & 67.68 & 68.25 & 62.40 & 56.70 & 55.14 & 54.47 \\
\hline 1000 & 3.00 & 63.04 & 66.87 & 74.02 & 82.98 & 67.51 & 65.89 & 66.66 & 60.73 & 54.47 & 53.25 & 52.63 \\
\hline 2000 & 3.30 & 61.37 & 65.54 & 73.07 & 82.17 & 65.67 & 64.41 & 65.01 & 57.61 & 52.55 & 51.34 & 51.41 \\
\hline 5000 & 3.70 & 59.26 & 63.94 & 71.87 & 81.14 & 62.99 & 62.35 & 62.76 & 56.40 & 50.94 & 49.48 & 50.32 \\
\hline 10000 & 4.00 & 57.65 & 62.79 & 71.07 & 80.36 & 60.67 & 60.16 & 61.39 & 54.44 & 50.08 & 47.85 & 48.64 \\
\hline 20000 & 4.30 & 56.15 & 61.70 & 70.24 & 79.60 & 58.90 & 58.34 & 59.89 & 53.59 & 48.45 & 45.92 & 47.72 \\
\hline 50000 & 4.70 & 54.33 & 60.44 & 69.26 & 78.59 & 56.55 & 56.61 & 57.80 & 51.97 & 46.37 & 44.06 & 45.96 \\
\hline 100000 & 5.00 & 52.99 & 59.58 & 68.67 & 77.70 & 54.11 & 53.84 & 56.98 & 50.33 & 46.19 & 42.74 & 45.37 \\
\hline 200000 & 5.30 & 51.64 & 58.49 & 67.79 & 77.08 & 52.25 & 51.97 & 55.00 & 49.50 & 45.29 & 41.57 & 43.82 \\
\hline
\end{tabular}


The results of relative stress relaxation of the different kinds of yarns at $3 \%, 5 \%, 7 \%$ and $10 \%$ elongation are presented in Figure 2.

As it is seen from Figure 2(a), the relative stress of the multifilament polyester yarn depends on the level of elongation. In the case of higher elongation, the relative stress is higher in the all periods of relaxation, too. While dynamic changes of the relative stresses are not the same. After $1 \mathrm{~s}$ of stretching up to $10 \%$, the relative stress is only in $6.77 \%$ higher than analogous value of relaxation at stretching up to $3 \%$, while after $200,000 \mathrm{~s}$ this difference reaches $33 \%$.

A different situation was observed in the case of the cotton yarn (see Figure 2 (b)). At first, it is necessary to note that the tensile elongation of the cotton yarn is only $7.41 \%$, and due to that, the tests of the stress relaxation were carried out only at $3 \%$, $5 \%$ and $7 \%$. For the cotton yarn, the relative relaxation under various stresses is almost the same. After $1 \mathrm{~s}$ of stretching up to $3 \%$ elongation level, the relative stress relaxation is only in $2.9 \%$ higher than analogous result in the case of $7 \%$ stretch. After $5,000 \mathrm{~s}$, the values of the relative stress relaxation became the limit of errors in all cases of strain, while after 200,000 s the values of relative stress relaxation at the level of $7 \%$ strain is $5.5 \%$ higher than the same values at the level of $3 \%$ or $5 \%$ strain. Thus, the difference exists but not as high as in the case of polyester yarns.

In Figure 2(c), the curves of relative stress relaxation of the woollen yarn are presented. In the woollen yarns case, the highest difference of the results of relative stress relaxation exists between the strain level of $3 \%$ and all the other strain levels $-5 \%$, $7 \%$ and $10 \%$. However, at the time of the long-lasting relaxation (starting from $100,000 \mathrm{~s}$ ), the differences between curves of $5 \%$, $7 \%$ and $10 \%$ are visible. Even more, the differences between shapes of curves of the woollen yarns and other types of yarns are visible - the rate of the stress relaxation changes after $100 \mathrm{~s}$ at a much higher level than in the case of the polyester or the cotton yarns. The obtained results proved the hypothesis of Morton [1], who stated that the woollen fibres have the most complicated structure, with ten levels of structure from fundamental particles to the whole fibre. It is a multicellular and multicomponent fibre. In particular, there are differences of composition between the crystalline microfibrils (intermediate filaments), which composes up to about $40 \%$ of the fibre and the amorphous matrix [1].

The comparison of the relative stress relaxation curves of the multifilament polyester, cotton and woollen yarns at different levels of elongation are presented in Figure 3.

As it is seen from Figure 3, the results of relative stress relaxation are similar for all types of the yarns only at the lowest level of strain, i.e at $3 \%$. In all other cases, the differences are higher and increase by increasing the level of strain (highest differences are at the level of $10 \%$ of strain). Herewith, the dependence of the relative stress relaxation on the logarithmic scale of time in a majority of cases does not have a linear character. Due to that, in the next step of our investigations we tried to check the possibility to use the method to predict long-lasting stress relaxation, which was developed for the polyester yarns (presented in our earlier published works [2, 32]), for all types of yarns and all strain levels.
The description of the relaxation process by two straight lines, depending on the place of the break-point, is presented in Table 3 and Figure 4 (according to the earlier presented method [2, 32]).

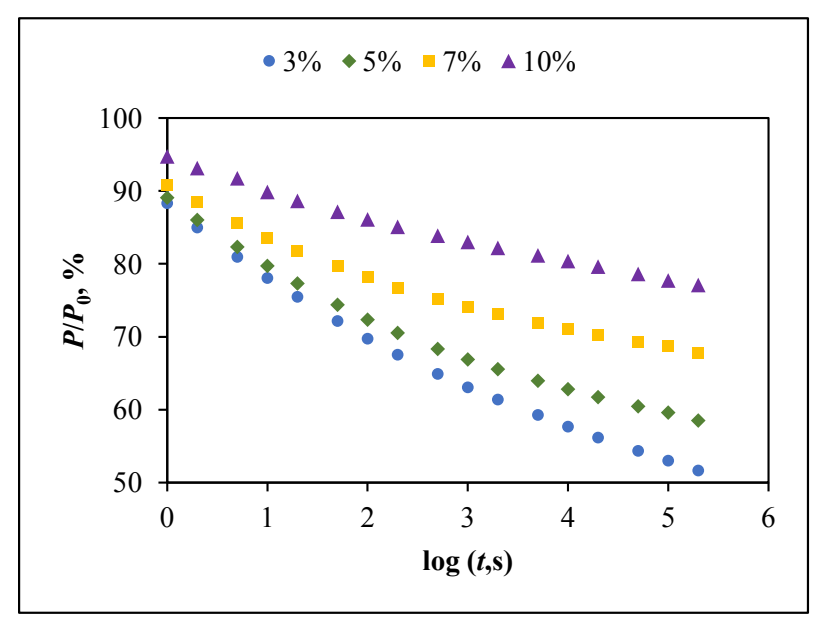

(a)

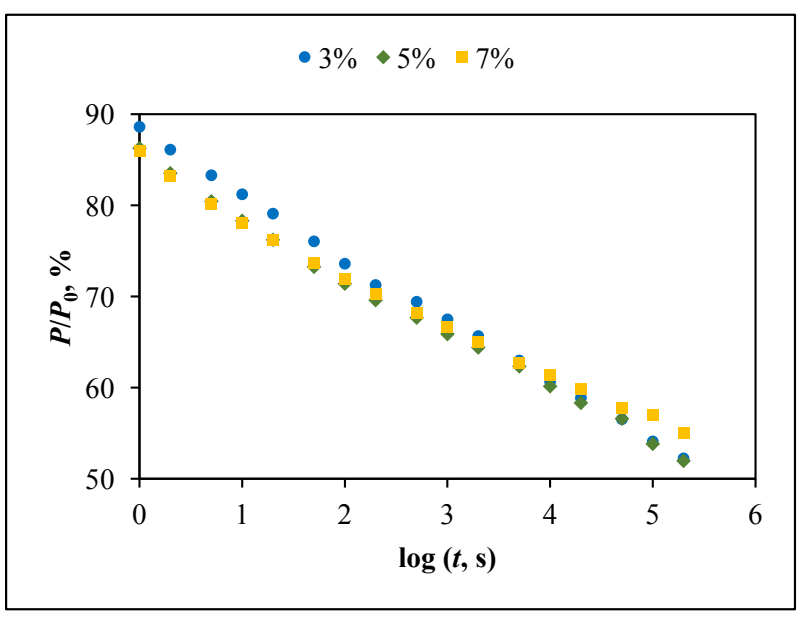

(b)

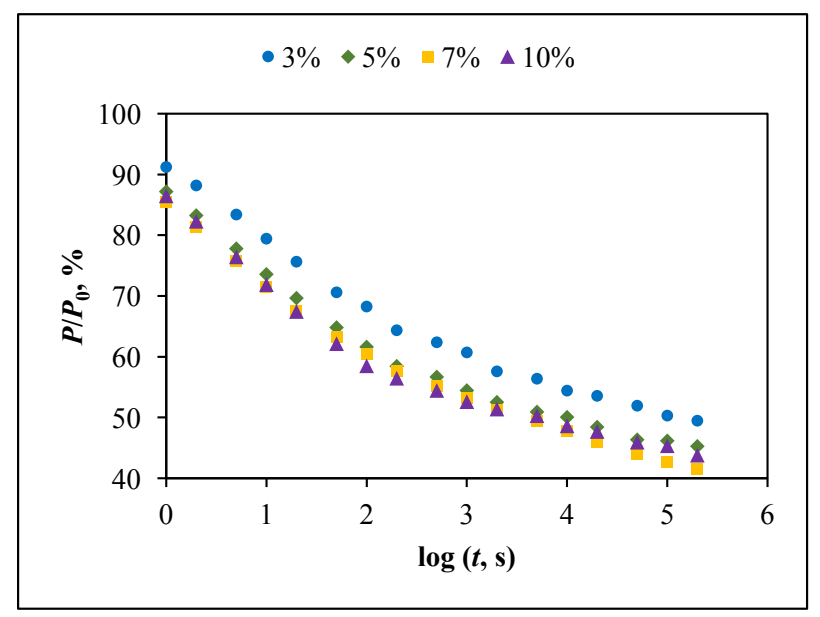

(c)

Figure 2. The relative stress relaxation curves of the yarns at different strain elongations: (a) multifilament polyester yarn, (b) cotton yarn and (c) woollen yarn. 


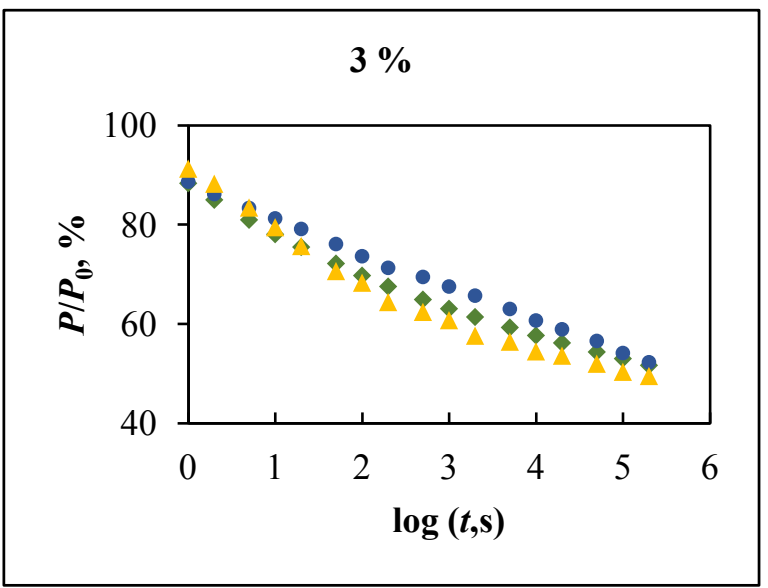

(a)

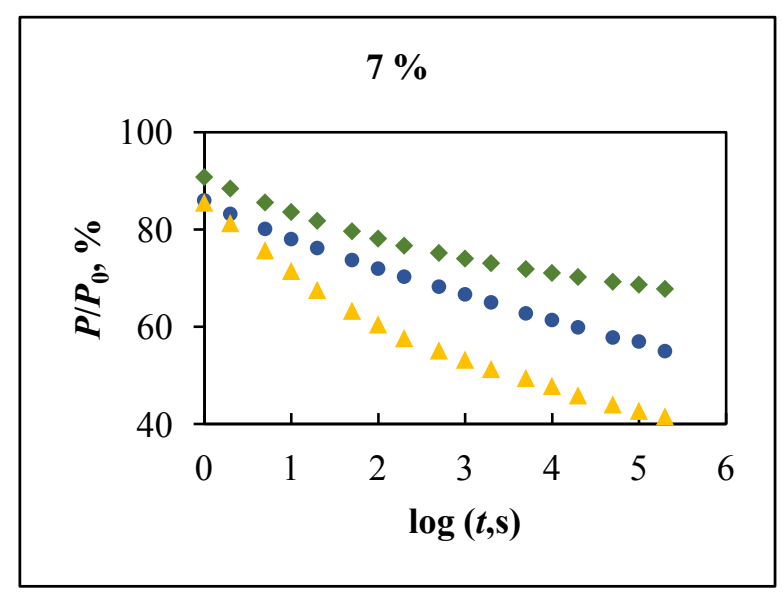

(c)

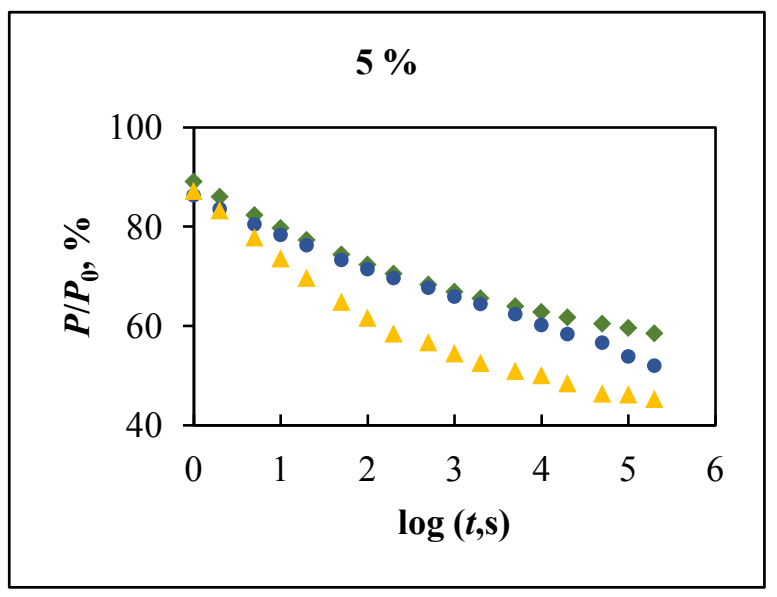

(b)

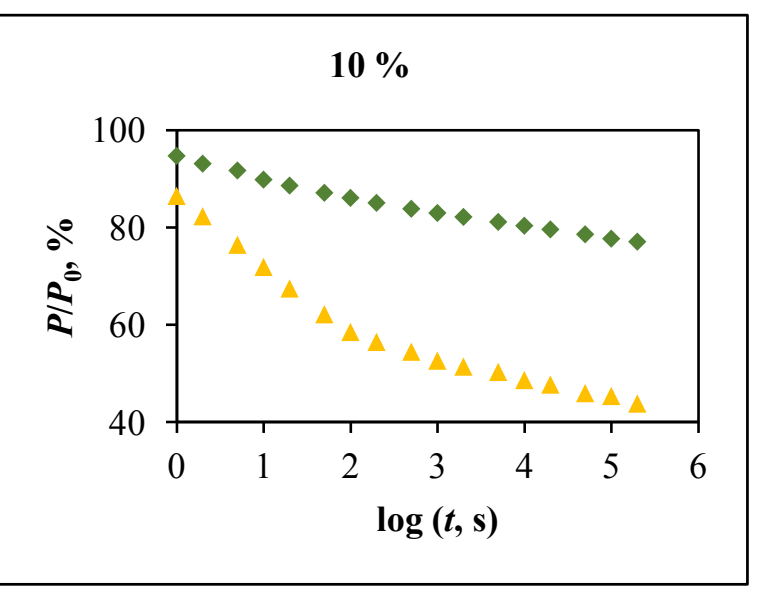

(d)

Figure 3. Relative stress relaxation curves of the multifilament polyester $-3 \%$, (b) $-5 \%$, (c) $-7 \%$, (d) $-10 \%$.

Table 3. Results of the maximum relative error at different places of the break-point in the cases of different levels of elongation

\begin{tabular}{|c|c|c|c|c|c|c|c|c|c|c|c|c|}
\hline \multicolumn{2}{|c|}{ Time } & \multicolumn{11}{|c|}{$\delta \max (\%)$} \\
\hline \multirow{2}{*}{$t(s)$} & \multirow{2}{*}{$\log (t, s)$} & \multicolumn{4}{|c|}{ Multifilament polyester yarn } & \multicolumn{3}{|c|}{ Cotton yarn } & \multicolumn{4}{|c|}{ Woollen yarn } \\
\hline & & $3 \%$ & $5 \%$ & $7 \%$ & $10 \%$ & $3 \%$ & $5 \%$ & $7 \%$ & $3 \%$ & $5 \%$ & $7 \%$ & $10 \%$ \\
\hline 5 & 0.70 & 2.74 & 3.02 & 2.19 & 1.39 & 1.28 & 1.28 & 1.37 & 6.57 & 8.12 & 6.35 & 8.00 \\
\hline 10 & 1.00 & 2.34 & 2.62 & 1.86 & 0.75 & 1.18 & 1.18 & 1.21 & 5.32 & 6.56 & 4.92 & 7.25 \\
\hline 20 & 1.30 & 2.15 & 2.28 & 1.59 & 0.60 & 1.04 & 1.11 & 1.10 & 4.44 & 5.36 & 3.78 & 6.17 \\
\hline 50 & 1.70 & 1.64 & 1.67 & 1.18 & 0.41 & 0.86 & 1.08 & 0.98 & 3.28 & 3.78 & 2.65 & 3.78 \\
\hline 100 & 2.00 & 1.23 & 1.29 & 0.92 & 0.30 & 0.74 & 1.07 & 0.91 & 2.94 & 2.77 & 1.97 & 1.61 \\
\hline 200 & 2.30 & 0.94 & 0.85 & 0.69 & 0.38 & 0.81 & 1.10 & 0.88 & 2.07 & 2.04 & 2.04 & 2.86 \\
\hline 500 & 2.70 & 1.48 & 1.56 & 1.19 & 0.58 & 0.86 & 1.24 & 1.08 & 2.87 & 4.37 & 3.90 & 5.62 \\
\hline 1000 & 3.00 & 1.79 & 1.90 & 1.31 & 0.67 & 0.93 & 1.18 & 1.26 & 3.77 & 4.57 & 4.56 & 6.19 \\
\hline 2000 & 3.30 & 2.22 & 2.27 & 1.59 & 0.77 & 1.14 & 1.38 & 1.41 & 3.02 & 5.14 & 5.09 & 7.43 \\
\hline 5000 & 3.70 & 2.95 & 2.98 & 2.03 & 0.97 & 1.28 & 1.63 & 1.54 & 5.66 & 7.36 & 6.93 & 9.86 \\
\hline 10000 & 4.00 & 3.14 & 3.22 & 2.23 & 0.98 & 1.31 & 1.56 & 1.68 & 5.57 & 8.55 & 7.20 & 9.44 \\
\hline 20000 & 4.30 & 3.44 & 3.49 & 2.37 & 1.11 & 1.37 & 1.64 & 1.82 & 6.97 & 8.48 & 8.98 & 10.20 \\
\hline 50000 & 4.70 & 4.25 & 4.24 & 2.77 & 1.25 & 1.44 & 1.80 & 1.96 & 8.28 & 13.19 & 8.48 & 10.96 \\
\hline
\end{tabular}




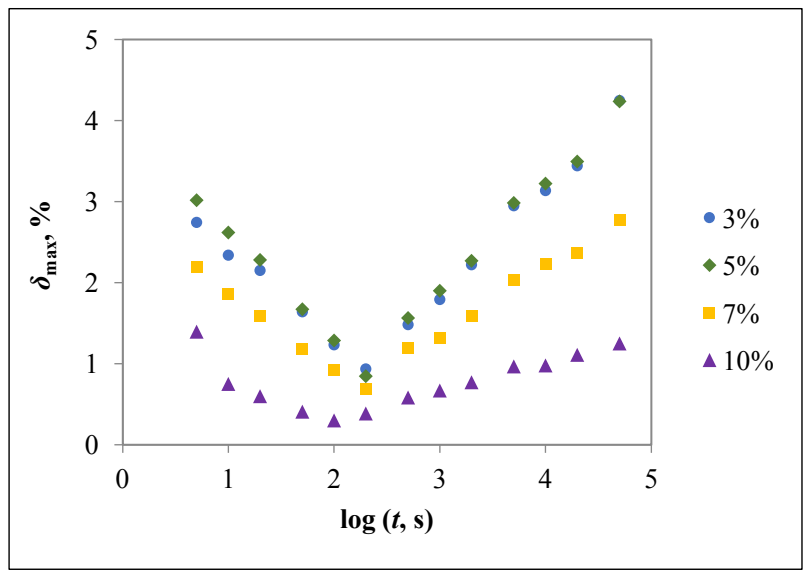

(a)

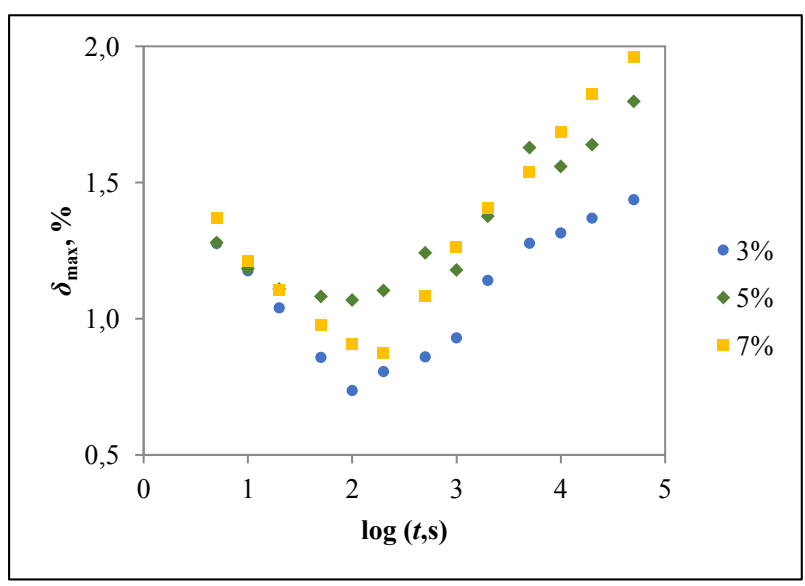

(b)

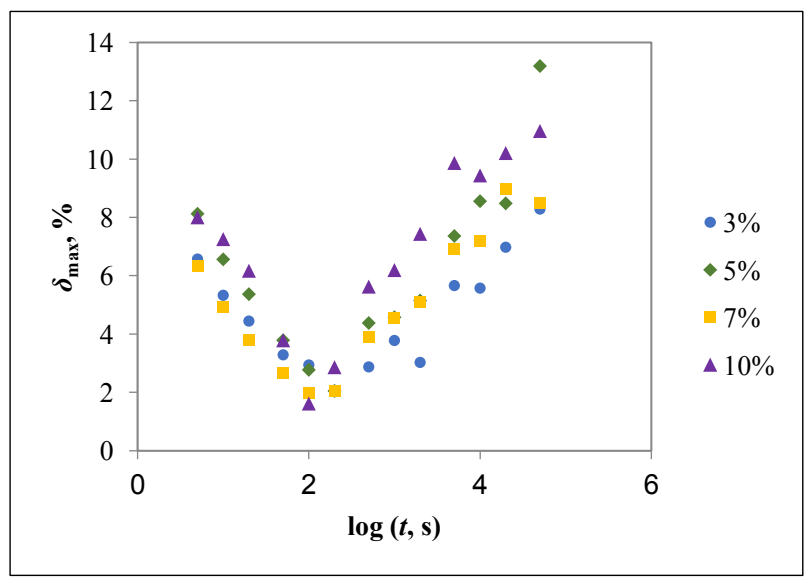

(c)

Figure 4. Dependences of maximum relative error on the time log $(t, \mathrm{~s})$ of different yarns and different levels of straining: (a) - multifilament polyester yarn, (b) - cotton yarn, (c) - woollen yarn.

As seen from Figure 4, the break-point was identified in the limits of 100 and $200 \mathrm{~s}$ of the relaxation in all cases. The differences between the yarns are not high: approximately the same time of the break-point was established in all cases. Depending on the level of strain, the place of break-point slightly moved from 200 to $100 \mathrm{~s}$ (by increasing level of the strain, the time till break-point decreases) and that is characteristic for all types of the yarns, even for cotton, which shows, at first view, different results of the relaxation. This phenomenon can be explained by the rate of rearrangement of macromolecules in polymer: higher the strain higher the initial speed of relaxation and the lower time till break-point is consequence of that.

Thus, we stated that the stress relaxation process of all types of the yarns in all cases of strain can be described by the same method, based on the break-point of relaxation rate. This empirical method can be used for predicting long-lasting relaxation without very long empirical investigations. It is enough to make relaxation tests only until 1000-2000 s and to calculate the break-point of relaxation rate. By the calculated second linear curve, it is possible to predict the stress relaxation in much longer time. In our case, we checked it till 200,000 s (more than $55 \mathrm{~h}$ ).

The presented phenomenon of the long-lasting stress relaxation behaviour can be explained by the structure of polymers, but the deeper analysis of theoretical reasons of this phenomenon is required. The authors would like to call other researchers to discuss such sophisticated phenomenon and to make the relaxation process clearer and more understandable for researchers as well as for users.

\section{Conclusion}

The relaxation behaviour of different types of yarns differs and the rate of relaxation is different, too. In majority of the cases, the relaxation rate and the shape of the relative relaxation curve depend on the level of strain. Despite the differences between the types of yarns, raw material and differences of relaxation in the cases of different levels of strain, the longlasting relaxation behaviour can be predicted by the breakpoint of relaxation rate and two linear dependences of the relative stress relaxation on a logarithmic scale of time. The investigations confirm earlier proposed hypothesis that the rate of stress relaxation in yarns changes after some time of relaxation and the decrease of the relaxation rate occurs in the area of 100-200 s after the relaxations starts. The break-point of relaxation rate was established in all cases - for all yarns and for all levels of strain. The method earlier presented by authors [2,32] was proved and the positive result was obtained in all the investigated cases.

\section{Acknowledgement}

The authors would like to acknowledge the contribution of the COST Action TU1303.

\section{References}

[1] Morton, W. E., Hearle, J. W S. (2008). Physical properties of textile fibres. 4th ed. Cambridge: Woodhead.

[2] Milašius, R., Laureckiene, G. (2014). Prediction of Longlasting Relaxation Properties of Polyester Yarns and Fabrics. FIBRES \& TEXTILES in Eastern Europe, 6(108), 97-100. 
[3] Baszczyński, K. (2015). Effect of Repeated Loading on Textile Rope and Webbing Characteristics in Personal Equipment Protecting Against Falls from a Height. FIBRES \& TEXTILES in Eastern Europe, 4(112), 110-118.

[4] Baltussen, J. J. M., Northolt, M. G. (2001). The viscoelastic extension of polymer fibres: creep behavior. Polymer, 42, 3835-3846.

[5] Hezavehi, E., Azadiyan, M., Zolgharnein, P. (2013). Investigation and Modelling of Stress Relaxation on Cylindrical Shell Woven Fabrics: Effect of Experimental Speed. FIBRES \& TEXTILES in Eastern Europe, 6(102), 64-73.

[6] Xia, N. N., Rong, M. Z., Zhang, M. Q., et al. (2016). Stress intensification - an abnormal phenomenon observed during stress relaxation of dynamic coordination polymer. eXPRESS Polymer Letters; 10(9), 742-749.

[7] Vangheluwe, L. (1993). Relaxation and inverse relaxation of yarns after dynamic loading. Textile Research Journal, 63(9), 552-556.

[8] Vitkauskas, A. (1997). Influence of alternating rate of extension on stress relaxation in textile yarns. Material Science (Medžiagotyra), 1(4), 52-57.

[9] Kothari, V. K., Rajkhowa, R., Gupta, V. B. (2001). Stress relaxation and inverse stress relaxation in silk fibres. Journal of Applied Polymer Science, 82, 1147-1154.

[10] Nachane, R. P., Sundaram, V. (1995). Analysis of Relaxation Phenomena in Textile Fibres Part I: Stress Relaxation. The Journal of the Textile institute, 86(1), 1019

[11] Manich, A. M., Ussman, M. H., Barella, A. (1999). Viscoelastic Behavior of Polypropylene. Textile Research Journal, 69(5), 325-330.

[12] Manich, A. M., Miguel, R., Lucas, J., et al. (2011). Texturing, stretching and relaxation behaviour of polylactide multifilament yarns. Textile Research Journal, 81(17), 1788-1795.

[13] Meredith, R. (1954). Relaxation of stress in stretched cellulose fibres. The Journal of the Textile institute, 45(6), T438-T461.

[14] Meredith, R., Hsu, B. S. (1962). Dynamic bending properties of fibers: Effect of temperature on nylon 66, terylene, orlon, and viscose rayon. Journal of Polymer Science, 61(172), 253-270.

[15] Suhara, F., Kutty, S. K. N., Nando, G. B. (1998). Stress Relaxation of Polyester Fiber-Polyurethane Elastomer Composite with Different Interfacial Bonding Agents. Journal of Elastomers and Plastics, 30(2), 103-117.

[16] Šajjn, D., Geršak, J., Flajs, R. (2006). Prediction of stress relaxation of fabrics with increased elasticity. Textile Research Journal, 76(10), 742-750.

[17] Geršak, J., Šajn, D., Bukosek, V. (2005). A study of the relaxation phenomena in the fabrics containing elastane yarns. International Journal of Clothing Science and Technology, 17(3/4), 188-199.

[18] Van Miltenburg, J. G. M. (1991). Stress Relaxation and Tensile Modulus of Polymeric Fibers. Textile Research Journal, 61(6), 363-369.
[19] Abromavičiūtè, J., Mikučionienè, D., Čiukas, R. (2011). Static Water Absorption of Knits from Natural and Textured Yarns. FIBRES \& TEXTILES in Eastern Europe, 3(86), 6063.

[20] Mikučionienè, D., Arbataitis, E. (2013). Comparative Analysis of the Influence of Bamboo and Other Cellulose Fibres on Selected Structural Parameters and Physical Properties of Knitted Fabrics. FIBRES \& TEXTILES in Eastern Europe, 3(99), 76-80.

[21] Malik, S. A., Farooqc, A., Gerekeb, T. et al. (2016). Prediction of Blended Yarn Evenness and Tensile Properties by Using Artificial Neural Network and Multiple Linear Regression. Autex Research Journal, 16 (2), 43-50.

[22] Munakata, H. (1964). The Stress Relaxation and Set of Wool Fibers with Particular Reference to Their Structure and Mechanical Properties. Textile Research Journal, 34(2), 97-109

[23] Kubu, E. T., Frei, F., Montgomery, D. J. (1954). The Stress Relaxation of Fibrous Materials III. Stress Relaxation of Wool Keratin in Water and in Salt Solutions. Textile Research Journal, 24(7), 659-662.

[24] Chapman, B. M. (1973). Bending stress relaxation and recovery of wool, nylon 66, and terylene fibers. Journal of Applied Polymer Science, 17(6), 1693-1713.

[25] Bandyopadhyay, S., Ghosh, A., Ali, S. Y. (2011). Tensile Fatigue, Stress Relaxation, and Creep Behaviors of Worsted Core Spun Yarns. Journal of Applied Polymer Science, 121, 2123-2126.

[26] Inoue, M., Niwa, M. (1997). Tensile and Tensile Stress Relaxation Properties of Wool/Cotton Plied Yarns. Textile Research Journal, 67(5), 378-385.

[27] Zhang, J. T., Zhang, M., Li, S. X., et al. (2016). Residual stresses created during curing of a polymer matrix composite using a viscoelastic model. Composites Science and Technology, 130, 20-27.

[28] Hashemi, N., Asayesh, A., Jeddi, A. A. A., et al. (2016). The influence of two bar warp-knitted structure on the fabric tensile stress relaxation Part l: (reverse locknit, sharkskin, queens' cord). The Journal of the Textile Institute, 107(4), 512-524.

[29] Ardakani, T., Asayesh, A., Jeddi, A. A. A. (2016). The influence of two bar warp-knitted structure on the fabric tensile stress relaxation Part II: (locknit, satin, loop raised). The Journal of the Textile Institute, 107(11), 1357-1368.

[30] Misak, H. E., Sabelkin, V., Miller, L., et al. (2013). Creep and Inverse Stress Relaxation Behaviors of Carbon Nanotube Yarns. Journal of Nanoscience and Nanotechnology, 13, 1-9.

[31] Babay, A., Helali, H., Msahli, S. (2014). Study of the mechanical behaviour of the elastic-core-spun yarns. The Journal of the Textile Institute, 105(7), 701-710.

[32] Laureckiene, G., Milašius, R. (2016). Influence of the Straining Level on the Long-Lasting Relaxation Behaviour of Polyester Yarns. FIBRES \& TEXTILES in Eastern Europe, 1(115), 73-77. 